\title{
A cintilância do espaço
}

\author{
Grazielle Katyane dos Santos Silva \\ (Universidade Estadual Paulista \\ UNESP - S. J. do Rio Preto)
}

\section{RESUMO}

Neste artigo, apresentamos uma análise da espacialidade do livro Os guardachuvas cintilantes (1984), da escritora portuguesa Teolinda Gersão. Trata-se de uma obra que nos conduz a uma perspectiva de análise que visa problematizar o gênero diário por meio de um trabalho textual que coloca em questão as tradicionais noções da narrativa, peculiares ao gênero diário. Em Os guardachuvas cintilantes há a tentativa de destruir a temporalidade linear e criar uma outra medida de temporalidade que se baseia em motivos lúdicos. A configuração da espacialidade, por sua vez, cruza o tempo e, assim, torna-se móvel e instável. Observa-se na obra a existência de múltiplos espaços: um espaço onírico, um espaço material e um espaço simbólico.

PALAVRAS-CHAVE: espacialidade, Os guarda-chuvas cintilantes, Teolinda Gersão.

\section{ABSTRACT}

This article presents an analysis of spatiality in the book Os guarda-chuvas cintilantes (Shimmering Umbrellas), 1984, written by the Portuguese writer Teolinda Gersão. The book makes us question the journal genre. However, the text itself questions the traditional notions of narrative, which are particular to the journal genre. In Os guarda-chuvas cintilantes there is the attempt to destroy linear temporality and create a new temporal measure, based on ludical themes, is also important in the book. The configuration of spatiality crosses time, becoming, therefore, mobile and unstable. There are in the book multiples spaces: a dream space, a material space and a symbolic space.

KEYWORDS: spatiality, Shimmering Umbrellas, Teolinda Gersão. 
Os universos ficcionais de Teolinda Gersão começaram a surgir, na literatura portuguesa, em 1981, quando a escritora decide passar a uma nova etapa de contato com a literatura, ou seja, conclui seu trabalho como docente e cede ao seu impulso inicial: escrever. Entre as narrativas de Teolinda Gersão, Os guarda-chuvas cintilantes (1984) apresenta-se como uma obra sui generis, despontando como uma peça fora do contexto. Essa afirmação se legitima pela rebeldia com que Gersão trata o tradicional, as formas fixas, seja no plano de expressão (diário), seja no plano do conteúdo (limites da realidade e do ser humano).

A singularidade de Os guarda-chuvas cintilantes manifesta-se, principalmente, no tratamento que se dá ao gênero diário. Rocha (1992) apresenta-nos, na literatura portuguesa, uma forte tradição autobiográfica, incluindo os gêneros diarístico e memorialístico. E Teolinda Gersão, em entrevista, comenta que, apesar de haver uma vasta produção desses gêneros, ainda não haviam feito um "anti-diário".

A aparente rebeldia, seja no tratamento do gênero, seja na expressão literária, pode ser constatada no trabalho de Teolinda. "Cumpre lembrar que a própria escritora manifesta-se contrária à tentativa de enquadramento ou 'arrumação' de seu texto" (Dias, 1992, p. 9), o que se confirma na escrita de Os guarda-chwvas cintilantes, em que há uma mostra da fuga ao enquadramento e uma manifesta (des)organização proposital. Esse aspecto justifica-se pela tentativa de "agarrar o mundo num gesto vivificante" (Malheiro, 1982, p.26), conferindo ao texto de Teolinda Gersão certa movimentação e uma ruptura com os modos tradicionais de narrar. O questionamento a respeito da esfera genológica ganha espessura na própria obra, uma vez que nela emergem discussões sobre o que é diário, o que é a forma do diário, acentuando, portanto, a natureza metalinguística da narrativa.

A obra de Teolinda Gersão pode ser concebida como um diário ficcional, marcado, porém, pela negação das características tradicionais do gênero. Mas, justamente em virtude da operação intensa da própria ficcionalidade, trata-se antes de um antidiário. Além da forte instigação aos paradigmas do gênero, desponta também o tratamento singular da temporalidade e da espacialidade, de modo a desvincular essas categorias da estruturação convencional da narrativa. Como diário, Os guarda-chuvas cintilantes estão calcados nas dimensões temporais e espaciais mais "definidas", porém, há a tentativa de anular tal característica. Por isso as teorias habitualmente empregadas para falar de tempo e espaço não se adéquam a uma obra que instaura um outro sistema espácio-temporal, o que nos levou a buscar apoio teórico nas fontes de Eco (2003) e Bachelard (1993), pois somente nesses teóricos encontramos caminhos mais adequados para tratar da questão espacial, tal como ela se configura na obra.

Os guarda-chuvas cintilantes abrem-se como um texto que nos convida ao movimento. Também por esse dinamismo, o livro apresenta uma escrita que se forma em meio a um movimento circular e espiralado, cujas voltas iconizam o retorno a um outro momento e a um outro espaço já frequentados.

Bachelard (1993), ao discutir a temática do espaço, afirma que "o exterior e o interior formam uma dialética de esquartejamento, e a geometria evidente dessa dialética nos cega tão logo a introduzimos em âmbitos metafóricos" (Bachelard, 1993, p. 215).

De fato, ao colocarmos o exterior e o interior como planos espaciais cartesianos, estabelecemos um limite estanque em que tudo haveria de se resolver pela oposição. Porém, quando falamos da multiplicidade de registros de Os guarda-chuvas cintilantes, enriquecida pela dimensão simbólica da narrativa, 
o modelo cartesiano de espaço deixa suas lacunas. Devido a essas lacunas, para haver a amplificação espacial, "a dialética do exterior e do interior se multiplica e se diversifica em inúmeros matizes" (Bachelard, 1993, p. 219).

Dentre os matizes que a narrativa de Os guarda-chuvas cintilantes traça, destacam-se com tons significativos a materialidade do espaço, a relação entre a espacialidade e a temporalidade, a confluência entre o espaço e o estado de alma das personagens e, por fim, a associação entre o espacial e o simbólico.

Jogo de espaços moventes, Os guarda-chuvas cintilantes convidam o leitor a estar livre da fixidez espacial e a entrar num mundo insólito, onde se pode estar em diversos espaços a depender do tempo do diário. As datas em destaque (itálico) podem ser consideradas um pequeno e precário limite, ironia da estabilidade provisória dentro da qual se organizam as estruturas narrativas, entre elas, o espaço.

O tempo do diário se compõe por meio de recortes dos dias, de modo que se tem sempre um intervalo que separa os registros do diário. Dada a inusual relação entre o tempo e o espaço e a condição instável da temporalidade, o espaço característico da obra parece ser o intervalo (que tem uma natureza de transitoriedade): a escrita se dá num intervalo determinado; as personagens dão-se a conhecer em intervalos; a temporalidade vem também de intervalos; e em intervalos se mostram os espaços físicos em que as ações se realizam. Intervalo que reforça o instantâneo, o qual se relaciona com o fotográfico e, desse modo, entre um flash e outro, revela-se um modo interessante de mostrar uma relação entre o verbal da narrativa e a focagem fotográfica.

Nunes (2002), ao abordar a relação entre o espaço e o tempo nas artes, assinala que há uma dominância do tempo na literatura, o que implicaria dizer que quando o tempo é dominante, a espacialidade é virtual, e que quando o espaço é dominante, a temporalidade é virtual.

Ainda que se considere com ressalvas a proporcionalidade mostrada por Nunes (2002), em virtude da escassez de exemplos, nota-se que a dominância do tempo é bastante significativa em Os guarda-chuvas cintilantes, inclusive porque o tempo acaba sendo também matéria da narrativa. A marcação da temporalidade neste diário, apesar de ilógica ("Domingo, um Sábado, três - Segunda, quatorze - Quinta, oito - Domingo, vinte e três - Sexta, doze Terça, oito'), traz a constância do tempo, seja porque as ações acontecem num determinado momento, seja porque a temporalidade serve ao gracejo da narradora ou é objeto de reflexão e distorção.

Menos explícitas são as referências ao espaço em que os eventos ocorrem, o que é decorrente do fluxo intenso de pensamentos, das interferências de outras personagens e da jocosidade de cunho surrealista. Observa-se que o espaço é rarefeito, resultando dessa rarefação a latência do espaço físico, o qual muitas vezes pode ser inferido sem qualquer marca de concretude. É o que ocorre, por exemplo, neste flash:

\section{Quarta, quinze.}

Ainda com respeito ao mesmo caso, leio no jornal de hoje: Quando se tornou conhecido, muitas mulheres foram tomadas de pânico e daí em diante passaram ao lado das vitrinas, o que levou à falência numerosos industriais do comércio de peles.

- Que história absurda, ri a Girafa vestindo o casaco e preparando-se para sair. A mim jamais me aconteceria uma história assim. (Gersão, 1997, p. 79-80) 
Depreende-se que a ação se passa na casa da personagem Girafa e de sua mãe, a narradora mais evidente desse diário que abarca múltiplas personagens e vozes narrativas. Embora não tenhamos nenhuma referência explícita à casa, pelo correr da narrativa, sabemos que Girafa é a filha da narradora e que ambas estão na casa em que moram, comentando um caso que saiu num jornal. A evidência do trecho faz a análise parecer tosca, porém, se se considera a variedade de registros do diário e a falta de referências significativas a tantas personagens e lugares que surgem na narrativa, ilustra-se bem a inferência sobre o espaço, ainda que não haja marca de espacialidade concreta.

As marcas de espaço concreto serão mais presentes quando há narrativas que incluem personagens que não atuam diretamente na vida da personagem-narradora, como ocorre, por exemplo, na "História da Neusa" ou na "História do quotidiano", em que há descrições pormenorizadas do espaço. Vale destacar que essas histórias formam-se como pequenos contos dentro da narrativa.

Aliás, a alternância dos registros do diário faz com que haja também uma alternância de espaços, a qual cabe bem no modelo intervalar (ou no click da câmera). Essa alternância será observada, sobretudo, quanto à materialidade espacial, uma vez que a obra reveza os registros de realidade narrativa, de sonhos e pensamentos. A começar, o espaço que inaugura Os guarda-chuvas cintilantes é totalmente evanescente, por se tratar de um sonho. Esse espaço evanescente, mais próximo ao abstrato, alterna-se com o espaço concreto, materialmente palpável. Tanto o evanescente quanto o concreto valem-se de elementos figurativos, porém o que os diferencia é a materialidade. Por exemplo, no sonho que abre a obra, há a imagem dos guarda-chuvas que fogem, em meio à chuva, da mulher que está na rua a persegui-los, ou seja, há elementos figurativos, porém não materiais já que são constituídos como sonho. Tais elementos voltam a aparecer, no decorrer da narrativa, com uma maior carga de materialidade; em alguns momentos, são totalmente materiais: o guarda-chuva é o guarda-chuva, a chuva é a chuva; em outros momentos, perde-se a materialidade, gerando conotações várias: o guarda-chuva passa a ser o tempo, ou a proteção, por exemplo. O intervalo, espaço característico da obra, evidencia o transitório como predicado. Haverá, portanto, o trânsito entre o evanescente e o material e vice-versa, além da alternância de locais que servem de alvo narrativo. Assim, do sonho passa-se à vida real, e vê-se surgir, por meio das descrições, "uma casa pintada de branco e de azul, no meio de um jardim tropical, quase inteiramente coberto por um jacarandá" (Gersão, 1997, p. 13), onde há um ambiente pacato, com duas crianças que brincam e que têm suas curiosidades pueris. Vê-se também a vizinhança: de um lado, uma simpática mulher, Chris, que foi abandonada pelo marido e vive com sua filha deficiente; de outro, uma casa onde há fantasmas de crianças que morreram afogadas, mas que estão presas à casa e choram.

Segundo Bachelard (1993), "Toda grande imagem simples revela um estado de alma. A casa, mais ainda que a paisagem, é 'um estado de alma'. Mesmo reproduzida em seu exterior, ela fala de uma intimidade" (Bachelard, 1993, p. 84). Se considerarmos a hipótese dessa psicologia sensitiva na análise do autor, veremos a confluência entre o espaço e o estado de alma da personagem narradora: há uma mulher que vive numa casa quase celestial, envolta nos pequenos afazeres diários e confinada às pequenas alegrias do lar, mas que possui também suas perturbações quase fantasmagóricas com a morte, a fatalidade, a inevitabilidade da passagem do tempo, a escrita, a criação, a desigualdade, as mesquinharias e lutas humanas; a vida em seu sentido lato. Ou seja, o espaço exterior - a casa e a vizinhança - figuram, no plano 
representativo, o interior da personagem: há o conforto e a paz, avizinhados pelas perturbações. Mas: tal figuração ou confluência entre o exterior e o interior não se dá em moldes românticos ou idealistas, nem realistas. O reflexo entre o anímico e o físico-natural é desestabilizado ou esvaziado idealisticamente pelo trato insólito e tendente ao fantástico que a narrativa antidiarística realiza.

Também a personagem Ana Maria, um alter-ego da personagemnarradora, possui um apartamento organizado, mas pequeno, pela burguesia que ela ostenta, para ser dividido por ela, pelo marido, pelas cinco crianças, pela babá e pela cozinheira. Mediante o registro da vida de Ana Maria, o espaço adquire o aspecto de limite cerrado, e Ana Maria, o protótipo da mulher encerrada pelas paredes, com o constante medo de que os filhos caiam pelas janelas do apartamento no $27^{\circ}$ andar. Ana Maria é extremamente ordeira e habilidosa para cuidar das necessidades do lar, mas também é tensa por causa dessas obrigações. O espaço físico representa, portanto, a combinação inquieta entre o conforto e a conturbação interna de Ana Maria.

A tensão maior virá, porém, não de Ana Maria, mas de uma outra personagem, não nomeada, cuja manifestação só pode ser percebida pelas formas verbais em terceira pessoa. Esta personagem está visitando o apartamento e se projeta em Ana Maria. Encerrada no mesmo ambiente do apartamento, ela o vê como opressor:

As pessoas viviam fora do seu habitat normal, sentiu olhando para baixo, aceitavam viver precariamente em jaulas e aquários, nadavam dentro de vidros e vinham de quando em quando à tona de água abrir a boca. Sufocadas. (Gersão, 1997, p. 94)

A imagem inóspita deste ambiente é composta, sobretudo, pelo estabelecimento do limite espacial: tanto a jaula quanto o aquário apresentam barreiras condicionantes, impostas sempre pelo contato que se tem com o outro. O relevante, porém, não é quem impõe o limite, mas o limite em si. É contra o limite que se briga; o limite é o próprio oponente porque é somente a ele que se deseja transcender.

A casa, então, ocupa um lugar relevante na narrativa, na medida em que presentifica as angústias íntimas das personagens. Todas as casas descritas - a da personagem-narradora, a de Ana Maria e a de Wanda, outra personagem, - têm em comum um estilo de vida pequeno-burguês, o que aparentemente deveria evitar-lhes uma série de desconfortos físicos. Porém, os desconfortos das personagens são de outra ordem: a fixidez que cristaliza a vida é o que as incomoda.

Contornando a fixidez, expõe-se a sugestão da fuga. Em diversos momentos, Os guarda-chuvas cintilantes trazem a fuga, não como solução, mas como alternativa: os guarda-chuvas fogem em sonho, o tempo foge no real, o gato foge do prédio, a palhaça Teté foge com o circo, a autoimagem da personagem foge-lhe, a sombra foge à captura da imagem fotográfica, os filhos que partirão um dia, a mulher que vira raposa e foge para se embrenhar na floresta, as palavras deslizam na escrita e há também Andersen, o escritor, que possuía uma corda para poder fugir pela janela.

Ora, pela própria dialética que movimenta o real, sabemos que para haver a fuga há de existir o limite. Observamos, então, mais detidamente, dois espaços-limite utilizados para realizar a fuga: a janela e o corrimão.

À personagem Ana Maria, como dissemos, assombravam as janelas pela possibilidade de que um dos filhos caísse. Durante o registro da vida de 
Ana Maria, ocorre-lhe uma visita - que é expressa pelas falas em terceira pessoa, conforme já mencionado. Essa visitante projeta-se em Ana Maria, vivendo naquele apartamento, cercada pelas paredes e sem terra à volta, o que suscita atenção especial à janela:

A janela como pano de fundo da sua vida, que se passara a recortar sobre esse espaço, escavado em branco e azul. Contra o qual ganhava uma nova dimensão. Porque agora era aí que tudo acontecia, como se se desenhasse em contraluz. A sua vida unidimensional ganhando de repente a desmedida profundidade da janela. [...]

O jogo de sedução e resistência, entre a janela e ela mesma. Até que a janela passava para dentro dela, instalava-se e abria-se dentro dela. (Gersão, 1997, p. 95-96)

A personagem que visita Ana Maria procura incorporar-lhe a vida, mas substitui o medo pelo desejo: faz com que a janela - antes alvo de preocupações - se transforme num instrumento criador que viabiliza o imaginário de vida no apartamento, porque só a janela permite o contato direto com o natural. Mudando a maneira de focar a janela, ou de desfocá-la do concreto para o abstrato, altera-se também a percepção da personagem-visita. Segundo Bachelard (1993), "deixando o espaço das sensibilidades usuais, entramos em comunicação com um espaço psiquicamente inovador" (Bachelard, 1993, p.210). De fato, a janela passa a ser o espaço-luz que se contrapõe ao escuro-angústia do apartamento, proporcionando renovar o fôlego diante da persistência da vida cristalizada. Esse espaço-luz, a janela, é tão intenso como sugestão libertadora que passa a constituir a própria personagem-visita, que está se imaginando Ana Maria. Tão forte é esse encontro que faz brilhar o limite entre a janela e a vida no apartamento e a imaginação rompe barreiras, literalmente, pois sugere que esse limite poderia ser facilmente rompido: "Até que ela punha um pé no parapeito e o outro pé no espaço e caía para fora - a janela como saída, o gesto libertador de cair fora, via-se cair, ela sendo Ana Maria" (Gersão, 1997, p. 96).

Dias (1992), ao analisar Paisagem com mulher e mar ao fundo (de 1982), também de Teolinda Gersão, assinala que a visão pela janela cria um espaço de dupla profundidade na medida em que remete ao interior e dá acesso ao exterior; e justifica essa duplicidade de visão porque exterior e interior "contaminam seus reflexos e aprofundam-se como visões de um círculo ininterrupto e reversível" (Dias, 1992, p. 31). Em Os guarda-chuvas cintilantes verificamos que a janela apresenta profundidade dupla, inserindo-se tanto como signo de perigo como também de libertação e de fuga, repetindo assim o duplo sentido do espaço da janela como acesso ao exterior ou retorno ao interior angustiante.

Dentre as fugas sugeridas, esta é a mais extrema porque situa a vida no seu limite. O gesto libertador é gerado pelo desespero, pela impossibilidade de continuar no espaço em que se encontra. Não há, portanto, uma descontração nesta fuga, ao contrário do que constatamos nos outros modos de fuga. A mesma sedução da fuga atinge a personagem Andersen, referência direta ao escritor dinamarquês Hans Christian Andersen, com o qual a personagem narradora dialoga, inclusive sobre escritos do autor. Ao falar da visita a Copenhague a personagem diz que havia visto a casa de Andersen, o qual guardava uma corda para poder fugir pela janela em caso de perigo ou de incêndio. 
Como podemos perceber, a janela é o espaço que proporciona uma saída para a personagem quando está num ponto extremo de sua existência, em que restar no mesmo lugar é também um perigo de morte. Porém, vale dizer, a janela é um espaço eufórico, pois permite a saída, a fuga.

Diferentemente da janela, o corrimão é o meio de fuga mais gracioso, criativo, próximo ao insólito. É por meio dele que se escorrega, de modo circense, para uma nova vida:

- fugir com o circo, transformar-se em trapezista ou em funâmbula, e ninguém a conhecer nunca mais. [...] Ou vestir-se de palhaço, porque ser palhaço era um destino afinal mais de acordo.

- É a chamada Teté, disseram-me uma noite em Lisboa, em casa de Ricardo. Toda a vida ela desejou ser palhaço.

$[\ldots]$

Com essas calças escorregou uma vez pelo corrimão da sua casa, e nunca mais voltou. Que pena a minha casa não ter corrimão, pensa-se, no fundo de mim, e suspiro. (Gersão, 1997, p. 26-27)

Por esse corrimão, a palhaça Teté, na realidade a linda portuguesa Teresa Ricou, havia fugido de casa aos 16 anos para viver uma vida plena de liberdade e diversão. Ser palhaço é, então, a forma de assumir uma máscara própria, uma identidade de felicidade aparente. A marca da descontração dada pela vestimenta caracteriza um ser que consegue rir em qualquer circunstância, que vê a realidade circundante como uma grande piada. A personagem narradora, ao conhecer Teté, apresenta-se também como palhaça. O papel cailhe bem com o humor que a personagem destila em muitas de suas falas; algumas vezes, esse humor aparece de forma bastante sutil, como é o caso da sentida constatação por sua casa não possuir corrimão. Neste momento, verifica-se uma semente de humor, envolta numa casca de leve pesar. Mas, ainda assim, o corrimão instaura a figura da facilidade, como constatamos num outro registro do diário: "toda a actividade remunerada é racional, além disso é muito fácil, apenas avançar com a mão deslizando por um corrimão já polido pelo passar de muitas mãos" (Gersão, 1997, p. 42). Nota-se nesse trecho uma grande abertura às diversas interpretações, mas, pensando-se na produção de um livro, passar pelo corrimão da fórmula, dos demais modelos de obras, implica dificuldades menores para a composição de uma obra. A personagem, porém, cai para o irracional e deixa o corrimão, atuando como a nossa palhaça que compõe uma história bastante insólita. Desse modo, o corrimão conquista o status de espaço que conduz da racionalidade para a irracionalidade, da seriedade para o cômico e, por que não, para uma criação mais livre de teorias.

Vimos até aqui dois caminhos de fuga, a janela e o corrimão, ambos componentes de uma casa, a qual pode ser vista em seu sentido estrito, lar, ou em sentido mais amplo, a escrita. E tivemos, segundo a nossa análise, duas palhaças: uma que se traja com vestes engraçadas e, às vezes, grotescas; outra que se pinta com as muitas tintas da escrita. Da casa, faltou, no entanto, a porta - o meio mais simples para a fuga. E a porta aparece num dos registros do diário em que se escreve uma autobiografia: "Um dia descobri a porta que fazia sair de casa. Esse foi o dia mais belo: o mundo estava lá fora." (Gersão, 1997, p. 98). A casa figuraria como elemento de opressão, tal como ocorre em Paisagem com mulher e mar ao fundo (1982), de modo que sair dela seria o gesto da libertação que daria novas oportunidades à personagem. A partir dessa 
descoberta, a personagem inicia-se no conhecimento do mundo e das peculiaridades de diversas coisas, abrindo-se para todas as possibilidades, inclusive sentar-se na lua para ver nuvens sobre a Terra. Descobre também as palavras e o seu poder de construção de mundos, ou ainda seu poder de desconstrução: "muni-me de paciência e desmontei o universo. Desviei todas as coisas do seu caráter, arranquei todas ao seu curso ou ao seu uso, para construir novas hipóteses" (Gersão, 1997, p. 99).

Nota-se neste registro um caráter metanarrativo: o escritor toma posse das palavras e, uma vez com esse domínio, os significantes podem ser arrancados de seu uso, e hipóteses novas, ou arranjos diversos, surgem, acompanhando novos significados. Tais arranjos destacam-se ao provocar estranhamento, já que o objeto é singularizado. Eis uma característica própria do procedimento artístico, conforme apontamentos de Chklovski (1971), fundamental à atitude desestabilizadora de condicionamentos e códigos, quer da realidade, quer da linguagem. Esse "desvio" proposital da narradora justifica, inclusive, o processo de feitura da obra, como o uso da forma do diário para criar um antidiário e a formulação de imagens desconcertantes, singulares. Nesse momento do diário já se admite a desorganização das estruturas. Ao passar pelas concepções sobre o espaço, a questão da casualidade da organização espacial é algo que se destaca:

[...] deixo-me seduzir pela idéia ingênua de que os mapas organizam o caos e o transformam em mundo. De que é possível medir o mundo girando em volta da sala, da mesa à estante, do isqueiro à rosa, da janela à porta, do tapete de lã ao tampo de vidro. [...] Viagens tão fascinantes como quaisquer outras, porque no universo não existem direcções. Estavam todas em nós, desde o princípio. Mas só depois de várias voltas ao mundo se descobre essa evidência. (Gersão, 1997, p. 14-15)

Em meio à descrição dos objetos da sala, levanta-se a hipótese da casualidade; toda a ordem não seria outra coisa senão uma sucessão de acasos, de modo que se poderia dizer tanto "da mesa à estante, do isqueiro à rosa, da janela à porta, do tapete de lã ao tampo de vidro" como da mesa à janela, da estante ao isqueiro, do tapete de lã à porta, do tampo de vidro à rosa. De modo que a organização do espaço não teria necessariamente um sentido, tudo resultaria de acasos, de relações fortuitas. Os mapas só fariam agrupar locais e dar-lhes nomes e, então, o caos se chamaria mundo.

Os mapas teriam, portanto, uma função elementar porque os sentidos não estariam numa organização prévia. $\mathrm{O}$ olhar condicionaria sentidos, medindo, selecionando, agrupando, o que desembocaria numa crença sobre a equivalência de todos os lugares: todas as viagens são igualmente fascinantes. Essa crença intensifica-se quando sujeita todas as direções ao interior do ser, anulando a noção de que haveria direções no mundo a seguir. Assim, todas as coisas teriam um mesmo nível de equivalência: tudo é tão importante quanto tudo. Tal equivalência seria muito bem representada, no campo simbólico, pelo cintilar dos guarda-chuvas: todas as cores, antes particularizadas, tornam-se cintilantes, mediante o movimento giratório, sendo a diferença entre elas o que cria a cintilância e as coloca em plano de semelhança.

Todavia não podemos deixar de notar que essa crença nas equivalências, a qual sugere todas as direções imanentes nos seres, apresenta afinidades com a filosofia Zen-budista. Eco (2003), ao falar sobre o espaço na pintura zen, assinala que: 
A pintura clássica Zen [...] valoriza também o espaço como entidade positiva em si, não como receptáculo das coisas que nele sobressaem, mas como sua matriz: nesse tratamento do espaço há a presunção da unidade do universo, uma onivalorização de todas as coisas: homens, animais e plantas são tratados no estilo impressionista, confundindo-se com o fundo. (Eco, 2003, p. 210)

Essa onivalorização, apontada no Zen-budismo, está presente em $O s$ guarda-chuvas cintilantes, operando uma diluição de importância nas histórias narradas, uma vez que tudo é matéria de narração. Tal diluição é tocante também em outros elementos da narrativa, como personagens que se misturam em meio a tantas histórias e em diferentes espaços.

Quanto ao espaço, podemos dizer que é uma "entidade positiva em si", pois é mais um dos elementos da narrativa. Algumas vezes, as anotações presentes no registro do diário recaem sobre as descrições do espaço, ainda que este não tenha a função de estabelecer significações mais profundas na narrativa, como acontece, por exemplo, com a descrição de Copenhague aliás uma das mais referenciais, atendo-se meramente aos detalhes de uma viagem. Um outro registro que apresenta o espaço como "entidade positiva em si" é aquele em que se descrevem as árvores que circundam a casa da personagemnarradora. Desse modo, o espaço não é só um elemento subjacente às ações do texto, mas é também um objeto da narrativa, um objeto tão importante quanto qualquer outro. Como os demais objetos da narrativa de Os guarda-chuvas cintilantes (entre eles o tempo, o eu, o diário, o narrador e as personagens), o espaço sofre a dispersão do centro, ou seja, não há um centro onde ocorrem os eventos, ou um espaço central e outros periféricos. Ex-cêntrico, esse universo insólito também se furta à fixidez, o que transparece no fragmento abaixo:

Em algum lugar deve haver uma folha de papel, uma mesa, uma cadeira, uma caneta e um recorte de silêncio em volta, pensou correndo pelo dia, em algum lugar do mundo deverei poder ficar sozinha, dar duas voltas à chave e encostar-me à porta, com o coração a bater com força, vencendo todos os obstáculos no último instante, como água galgando um dique e atingindo um campo, correrei sobre um campo gritando em triunfo, e os quatro ventos me levarão consigo, para norte e para sul, para oeste e para leste, não há limite, gritarei empurrando as paredes, deitando abaixo com o corpo todas as paredes, (Gersão, 1997, p. 47)

Essa negação do limite espacial, tal qual a do tempo, apresenta uma particularidade: vem contígua ao estabelecimento de um modelo, o qual se dá pela oposição ao limite. Ou seja, a negação do limite acaba por ajustar a imagem do espaço a algo ilimitado, de modo que a personagem pode, ao fechar de uma porta, integrar-se ao espaço como um todo, estando plenamente no norte, no sul, no leste e no oeste, porque seria levada, simultaneamente, por quatro ventos para quatro direções que não se distinguiriam mais. $O$ movimento do corpo que possui em si as direções vai se ampliando, ao longo do discurso enunciativo, devido ao uso das formas nominais "correndo", "vencendo", "galgando", "atingindo", "gritando" e "deitando". O sufixo formador do gerúndio traça o movimento dos verbos com aspecto incoativo; assim, a sequência dos verbos enunciados, que caracterizam ações dependentes 
de um agente, servirá para mostrar uma sucessão de passos que conduzem à chegada a um plano mais vasto, ao "triunfo".

Além da presença das formas do gerúndio, o crescente da ação se dá também por meio da imagem da água que galga um dique, atingindo um campo. O verbo "galgar" solicita alguns predicados, entre eles a agilidade e a velocidade, que o tornam praticamente imperioso. Desse modo, a imagem vem rolando pelas formas do gerúndio e assomando em velocidade à vastidão do campo. Ante a força do verbo "galgar", o vocábulo "dique" parece diminuído, chegando quase a uma pedra, não tão grande, no caminho.

Em Os guarda-chuvas cintilantes, a transposição de um obstáculo, de qualquer obstáculo, compõe-se de uma negação. Trata-se, porém, de uma negação que sugere outros modelos afirmativos. Assim, não só se nega o limite espacial como também se propõe um outro referencial de espaço:

\section{Quarta, cinco.}

O que era uma forma alargada de outra biografia anterior, incisiva e breve e em forma de poema, que dizia simplesmente: Não sou de nenhum lugar.

O meu país é o vento

E os caminhos do mar. (Gersão, 1997, p. 102)

Nesse excerto, não se encontra nenhuma referência sobre origem, pois, no primeiro verso do poema, nega-se tanto a origem quanto o pertencimento a um lugar específico. Porém, o eu-lírico do poema situa-se em um lugar-nenhum, no seu país vento, o qual não pode ser nunca delimitado por ser móvel. Tanto o vento quanto o mar são móveis, e suas direções, muito incertas. Além disso, há a vastidão do mar. Assim, a naturalidade do eu-lírico deve-se não à sua origem no espaço, mas à integração ao natural.

Desse modo, o referencial de espaço que se apresenta ao negar os limites espaciais caracteriza-se pela vastidão, pelo aspecto amorfo e móvel, cuja única constância parece ser a eterna modificação que não permite limites muito sólidos. Há também em Os guarda-chwvas cintilantes um outro tipo de espaço, que não se caracteriza como materialmente concreto ou evanescente, tampouco estabelece relação com a temporalidade ou com o estado de alma das personagens. Trata-se de espaços que correspondem a um nível de representação mais simbólico. Analisamos a associação entre o espacial e o simbólico mediante dois trechos. No primeiro deles, o simbólico provém das cores do calçamento:

Elza ia na rua e pisava apenas as pedras brancas, disse. Por isso não choveria, haveria sol, o vestido de montra não custaria mais dinheiro do que ela tinha, António telefonaria e ter-lhe-ia trazido de Rabat um lenço de seda. Mas se pisasse as pedras pretas a ecografia acusaria um tumor que quando fosse ver era maligno, ninguém responderia ao anúncio que ela pusera e nunca mais conseguiria emprego em parte alguma. (Gersão, 1997, p. 15-16)

Nesse trecho, o calçamento formado pela justaposição de pedras brancas e negras não é somente o espaço físico por onde se passeia. A personagem Elza inicia a brincadeira infantil que associa o branco à realização dos desejos e o negro a infortúnios. O espaço passa a ser mais lúdico do que 
físico, e o estado de atenção que a cor das pedras desperta acaba por ser tragicômico, pois a personagem é uma mulher adulta que parece estar resolvendo seu destino à medida que pisa o chão. Assim, o branco e o negro são os espaços de sorte e revés, respectivamente; e o simbólico das cores determina o melhor espaço para se caminhar.

O espaço também figura como entidade com valores positivo e negativo ao associar-se à imagem do guarda-chuva e do guarda-sol:

As pessoas debaixo dos guarda-chuvas, sem cabeça, só se viam o tronco e as pernas, andando, [...] curvadas, encolhidas, fugindo, avançando o mais depressa possível, cosidas às paredes, procurando a protecção dos toldos, das sacadas, dos alpendres. Cinzentas, moles, irritadiças, baças [...] era melhor desaparecerem e cederem o seu lugar aos guarda-chuvas que passavam a ser na rua as personagens principais, todos diferentes, multicores, redondos, brilhantes de água, abrindo de prazer.

Mas tudo era diferente quando eram guarda-sóis e as pessoas ficavam em baixo, nimbadas de ouro, o guarda-sol existia então apenas frouxamente em si mesmo e a sua principal função era chamar a atenção para as pessoas que os transportavam e eram o seu foco e o seu centro, e avançavam direitas, triunfantes, como se irradiassem luz. (Gersão, 1997, p. 62)

O guarda-chuva, exercendo sua função de proteger da chuva, formase como espaço de irritabilidade, enclausurando todos que precisam dele como um pequeno teto, mas que, devido à chuva, devem recolher-se e se sujeitar a estar sob, numa posição em que os grandes destaques não são as pessoas, mas os guarda-chuvas. Já o guarda-sol teria como função apenas proteger do excessivo sol, de modo que ele não se torna maior que as pessoas que abriga; ao contrário, destaca-as sob o dourado do dia.

As circunstâncias em que são utilizados o guarda-sol e o guarda-chuva fazem com que o espaço de guardar as pessoas assuma valores diferentes. $\mathrm{O}$ símbolo do guarda-chuva associa-se, assim, ao cinzento, a uma pequena opressão; enquanto o símbolo do guarda-sol parece remeter sempre ao brilho e ao esplendor, não solicitando nem mesmo a imagem negativa do calor escaldante.

Observa-se, portanto, que os valores aplicados ao espaço não dependem, muitas vezes, do espaço em si, mas sim da relação que esse espaço estabelece com outros elementos, como o símbolo, por exemplo. Além disso, notamos que a abordagem do espaço na narrativa de Os guarda-chuvas cintilantes requer que esse elemento seja analisado sob diversos ângulos, considerando seus diferentes matizes.

A própria imagem do guarda-chuva, com suas múltiplas varetas, pode simbolizar ainda a divisão do espaço. Mas, quando os guarda-chuvas cintilam em seu rodopiar, não é mais possível isolar espaços. Assim, vemos surgirem esses espaços cintilantes, esse caos sem mapas que o organize, essas tantas direções que conduzem para onde também nos conduzimos. 


\section{REREFÊNCIAS BIBLIOGRÁFICAS}

BACHElARD, G. A poética do espaço. Trad. Antônio de P. Danesi. São Paulo: Martins Fontes, 1993.

CHKLOVSKI, V. A arte como procedimento. In: TOLEDO, D. O. (org.). Teoria da literatura - formalistas russos. Porto Alegre: Globo, 1971, p. 39-56.

DIAS, M. H. M. O pacto primordial entre mulher e escrita na obra ficcional de T.G. 1992. 264 f. Tese de Doutorado em Literatura Portuguesa, FFLCH, Universidade de São Paulo, São Paulo.

ECO, U. Obra aberta. São Paulo: Perspectiva, 2003.

GERSÃO, T. Paisagem com mulher e mar ao fundo. 4. ed. Lisboa: Dom Quixote, 1996.

. Os guarda-chuvas cintilantes. 2. ed. Lisboa: Dom Quixote, 1997.

MALHEIRO, M. H. Paisagem: espelho do mundo. Jornal de Letras, Artes e Idéias, Lisboa, ano II, n. 45, 1982, p.26.

NUNES, B. O tempo na narrativa. São Paulo: Ática, 1988.

ROCHA, C. Máscaras de Narciso - Estudos sobre a literatura autobiográfica em Portugal. Coimbra: Almedina, 1992. 